P158 (continued)

Theory, Prior Research, Rationale: The project was informed by Deardorff's Process Model of Intercultural Competence and the concept of "digital citizenship" which promotes competence in the use of internet-related tools to foster civic engagement.

Target Audience: Students in two community nutrition (CN) courses at University of Costa Rica (UCR) and Western Michigan University (WMU).

Description of Course or Curriculum: Four activities were integrated into the existing $\mathrm{CN}$ courses in each country. Students produced and posted 30-second autobiographical videos in native language, watched classmates' videos via UCR website, created a list of questions about the other's country pertaining to public health and community nutrition, interacted with students from the other country to address these questions, and presented findings to classes in real time via Skype.

Evaluation: Students $(n=38)$ provided feedback to improve the experience, by completing an 8-item survey with multiple choice and open-ended questions. Participating in the group Skype call was rated as the most helpful activity. The interest for topics addressed through this project increased in $21 \%$ of participants, and $84 \%$ would recommend the activities for future $\mathrm{CN}$ courses.

Conclusions and Implications: Students enriched their learning by exposure to the health system, professional roles, and community nutrition practices of a country different than their own. With suggested improvements, this low-cost activity can be replicated as a way to encourage international collaboration in the classroom while practicing web-based skills.

Funding: None

\section{P159 In Defense of Food (IDOF) Curriculum: A Formative Evaluation of an Afterschool Middle-School Intervention}

Hiershenee Bhana, MHSc, hiersheneebhana@gmail.com, Columbia University, 525 West 120th Street, New York, NY 10027; I. Contento, PhD; P. Koch, RD, EdD;

H. L. Gray, PhD, RD; C. Uno, MLIS

Objective: This formative evaluation examined the impact of the In Defense of Food (IDOF) Curriculum aimed at decreasing intake of highly-processed foods (HPF) and increasing intake of fruits and vegetables (FV).

Target Audience: The study was conducted in 3 afterschool classrooms in urban low-income neighborhoods with 32 multi-ethnic middle-school aged children.

Theory, Prior Research, Rationale: Social cognitive theory and self determination theory served as the theoretical framework to develop preferences and cognitive selfregulation skills needed for autonomous motivation to successfully navigate a complex food supply.

Description: The curriculum provided experiential activities including: preparing and eating whole plant-based foods, learning marketing techniques used to convince people to purchase HPF, performance poetry, and peerto-peer learning. Throughout, students investigated
"What should I eat to be healthy?" by thematically following Michael Pollan's axiom "Eat Food. Not too Much. Mostly Plants," and Pollan's Food Rules provided memorable ways for students to put what they learned into action in their lives. Film clips from the IDOF documentary were viewed during each lesson.

Evaluation: Students received 10 weekly 2-hour sessions. A pretest-posttest evaluation design using a previouslyvalidated survey, measured FV and HPF consumption and theory-based determinants. Paired t tests revealed significant behavior changes: students decreased intake of HPF $(p=0.04)$ and increased intake of FV $(p=0.0001)$. Theory-based determinants changed significantly for FV: beliefs $(\mathrm{p}=0.01)$ and self-efficacy $(\mathrm{p}=0.009)$ but not autonomous motivation and goal setting skills.

Conclusions and Implications: Results suggest food tasting and preparation experiences, eating whole foods with peers, using film clips, and providing actionable rules provide a promising approach to nutrition education in this context.

Funding: None

\section{P160 Qualitative Needs Assessment:} Pedagogical and Pragmatic Considerations for Afterschool Nutrition Education Programs

Hiershenee Bhana, MHSc, hiersheneebhana@gmail.com, Teachers College, Columbia University, 525 West 120th Street, Box 137, New York, NY 10027; I. Contento, PhD; P. Koch, RD, PhD

Objective: Little information is available about planning effective nutrition education in afterschool settings. The purpose of this study was to examine the perspectives of teachers and afterschool program coordinators on the positive aspects and challenges of afterschool education for middle school-aged children in order to guide the development of a nutrition education (NE) curriculum.

Design, Setting, Participants, and Intervention: Thirty-minute semi-structured in depth interviews with a purposeful sample of 4 teachers and 8 afterschool program coordinators were conducted. Teachers had an average of 12.6 years of teaching experience; and program coordinators were selected from non-profit and public sectors with experience serving at-risk youth.

Outcome Measures and Analysis: Interviews were audio-recorded, transcribed verbatim, and analyzed using inductive content analysis to identify, count, and compare themes. Content analysis of themes was performed using QSR-NVivo.

Results: Themes were organized into two meta-themes: pedagogical elements for successful learning with this age group; and pragmatic considerations for hosting NE programs in the afterschool context. Four pedagogical elements were derived as specific and essential for afterschool programing: the importance of studentcentered learning, such as "voice and choice" activities; use of scaffolding strategies; differentiation strategies to 